\title{
Pedro Zulen, filósofo revolucionario
}

Osmar GONZALESALVARADO

\section{RESUMEN}

En este artículo el autor se refiere a la figura de intelectual que el filósofo Pedro Zulen representa en el proceso intelectual peruano dentro del contexto dinámico social, cultural y políticamente hablando que vivió el país en las primeras décadas del siglo XX, tiempo fundamental y renovador de la vida nacional. Para ello, recorre su biografía, explora sus ideas y lo vincula a otros importantes pensadores de su época.

PALABRAS CLAVE: Pedro Zulen, intelectual, revolución, socialismo, indigenismo.

\section{PedroZulen, a revolutionary philosopher}

\section{ABSTRACT}

In this article, the author makes reference to the intellectual figure which the philosopher Pedro Zulen represents in the Peruvian intellectual process within the social, cultural and political dynamic context which the Peruvian society experienced in the first decades of the XXth century, critical times of renewal of national life. For that, the author explores Zulen's ideas and relates him with other important thinkers of his times.

KEYWORDS: Pedro Zulen, Intellectual, Revolution, Socialism,Indigenism. 
n el multiverso de los intelectuales peruanos del siglo anterior, emerge la figura de Pedro Salvino Zulen, usualmente cubierta de cierta atmósfera gris que impide ver su real importancia en el pensamiento social de nuestro país, aunque en la presente centuria han aparecido estudios sobre dicho filósofo que han contribuido a obtener una idea más precisa de su figura. Recientemente, Rafael Quiroz, Pablo Quintanilla y Joel Rojas lo han descrito como "uno de los filósofos peruanos más interesantes e importantes del siglo XX"1; incluso en la Universidad de San Marcos se ha constituido un grupo de estudio con su nombre que analiza y difunde su pensamiento. En la actualidad se vive un momento de rescate y reconocimiento de la importancia de Zulen en el proceso de las ideas en el Perú.

Con José Carlos Mariátegui, Zulen había quedado constreñido a su papel de impulsor decidido de la Asociación Pro-Indígena pero, siempre según el Amauta, desde una posición humanitaria y filantrópica; y no mucho más que eso. Sin embargo, últimamente ha aparecido una serie de libros y artículos que ofrecen una mirada más cabal de la obra de Zulen. No cabe duda que el Archivo Pedro Zulen Aymar que resguarda la Biblioteca Nacional del Perú, y sobre el cual Jorge Paredes Lara² realizó un valioso panorama, ha sido fundamental para que Zulen haya atraído el interés de los investigadores con nuevas miradas, más allá de la Pro-Indígena, y de la ficticia relación amorosa con Dora Mayer que ella misma se encargo de difundir con desmesura y alto grado de irrealidad.

En este artículo me quiero referir a la figura de intelectual que Zulen representa en nuestro proceso intelectual en el contexto dinámico social, cultural y políticamente hablando que vivió el Perú en las primeras décadas del siglo XX, tiempo fundamental y renovador de la vida nacional.

Saby Lazarte Oyague periodiza en tres momentos el proceso intelectual de Zulen: 1904-1911 son los años del tránsito del positivismo al pragmatismo; 1912-1918 son los del deslinde social-humanista, y 1920-1925 son los que cobija el debate académico-filosófico ${ }^{3}$.

Me valgo de esta cronología para, en la primera parte, seguir la evolución personal e ideológica de Zulen ubicándolo dentro de una franja generacional intermedia entre el novecentismo y el centenarismo y relacionarlo con otros pensadores e ideólogos de su tiempo con los que mantuvo vínculos personales (Joaquín Capelo, Dora Mayer, José María Eguren, José Carlos Mariátegui, Julio C. Tello); destacó su defensa del indio y la formación de la Asociación de la Pro-Indígena en 1909, así como las publicacio-

1 Rafael Quiroz, Pablo Quintanilla y Joel Rojas, Pedro Zulen. Escritos reunidos, Fondo Editorial del Congreso, Lima, 2015, 17.

2 Jorge Paredes Lara, "El novecentista Pedro Zulen y la Asociación Pro-Indígena a través del Archivo Histórico de la Biblioteca Nacional del Perú", Fénix núms. 40-41, 1998-1999.

3 Saby Evelyn Lazarte Oyague, El pensamiento filosófico de Pedro Zulen, Universidad Ricardo Palma, Lima, 2014.

\section{4/ REEUSTA DE SOCOOLOGÍA 26}


nes que impulsó y su participación en el periodismo. En la segunda parte me centro en sus ideas propiamente sociales que revelan su intento frustrado de ingresar a la política, su radicalización ideológica - exponiendo sus ideas sobre la revolución y el socialismo-, así como la crítica que esboza al orden político y social que mantenía en la opresión al indio.

No abordaré, salvo cuando sea estrictamente necesario, sus ideas filosóficas, sobre las cuales académicos con mayores méritos que yo han reflexionado ${ }^{4}$; me circunscribo a sus ideas sociales.

\section{Pedro Zulen y otros pensadores sociales de su tiempo}

Pedro Zulen se ubica en una franja de pensadores que se inicia con Manuel González Prada y concluye con José Carlos Mariátegui y Víctor Raúl Haya de la Torre. Cronológicamente, pertenece a la generación del Novecientos, aunque sus planteamientos difieren en mucho de las propuestas de, entre otros, Víctor Andrés Belaunde, José de la Riva Agüero o Francisco García Calderón, los intelectuales arielistas. Por la fecha de su nacimiento (Lima, 12 de octubre de 1889), se puede decir que Zulen es parte de esos intelectuales "bisagra" entre el Novecientos y el Centenario, de un grupo generacional al que pertenecen Luis E. Valcárcel (1891), José Antonio Encinas (1888), Abraham Valdelomar (1888), Alfredo González Prada (1891), Federico More (1889), y otros. Pero no se trata solo de una cuestión de fechas, sino, sobre todo, de las ideas que enarboló: principalmente la defensa radical del indígena — que no fue solo legal sino también de denuncia de un sistema de dominación construido por el latifundismo - ; oposición a la política pro inmigración de las consideradas "razas superiores"; defensa de la importancia andina en la formación de la nacionalidad y de la condición de ciudadanos que debe ser reconocida a los indígenas; crítica a la vida política, a la pobreza intelectual y universitaria, al centralismo; y, finalmente, a lo que llama ficción de la nacionalidad.

En este sentido, Zulen fue un observador agudo de la vida social peruana. Concurrentemente, Valdelomar, que empezaba a abandonar sus poses de dandismo iconoclasta, denunciaba al gamonalismo en sus discursos patrióticos, proceso en el que lo sorprendió la muerte en 1919. Por su parte, Encinas articulaba su propuesta pedagógica con la reivindicación del indio, y Valcárcel iniciaba sus estudios históricos sobre la realidad andina. En común tenían que iban organizando un discurso y una mirada sobre los problemas nacionales con un contenido cada vez más social que se

4 Augusto Salazar Bondy, Historia de las ideas en el Perú, Ed. Moncloa, Lima, 1965; David Sobrevilla, La filosofía contemporánea en el Perú, Mantaro, Lima, 1996. 
iba radicalizando, diferenciándose de los arielistas, pero sin llegar aún a las ideologías revolucionarias de los radicales del centenarismo. Hago la observación de que me detengo en 1925, año del fallecimiento de Zulen para contextualizar sus ideas en confrontación con las de sus contemporáneos.

\section{Datos de una vida}

Pedro Zulen provenía de una familia modesta que vivía en la calle Boza, en el Centro de Lima. Su padre, Pedro Francisco Soo Len ${ }^{5}$, fue de aquellos inmigrantes asiáticos que se incorporaron a la vida criollo-popular de Lima, con todas las dificultades que ello suponía en la medida de los prejuicios que prevalecían sobre la población asiática en general ${ }^{6}$. Su madre fue Petronila Irene, quien era iqueña y muy joven cuando se casó, solo tenía 17 años, mientras don Pedro Francisco ya contaba con 33 años. Es fácil suponer que la vida familiar, amplia —Pedro era el mayor de ocho hermanos- ${ }^{7}$, con madre provinciana y padre inmigrante, estuvo marcada por las diferentes proveniencias culturales, y que establecer el diálogo y el equilibrio familiar fue el resultado de un proceso de mutuas concesiones, que levantaron murallas afectivas que los protegieron de los prejuicios de la sociedad limeña de su época.

5 Según Richard Chuhue, en “Pedro Zulen o Sū Tíng Pèi Dé Luó (蘇廷·佩德罗), “hay cierta versión que recoge Ignacio López Calvo acerca del padre del filósofo, que señala que don"Pedro Francisco Zulen (Yua Zung Teng), fue un inmigrante de la provincia de Cantón quien trabajó en plantaciones costeras y posteriormente fue dueño de un negocio de empaquetadora de té". Revisando un "documento proveniente del archivo familiar [...], el padre firma en hanzi, o sea en caracteres tradicionales chinos". Según algunas expertas, "la primera grafía corresponde al término «Gù» (贵) y es usado como nombre propio, significando «noble»" (aunque su acepción más cotidianamente usada es «caro» u «oneroso»). La segunda grafía es también un nombre y se lee «Tíng» (廷), en tercer tono. Se complementa con el primer carácter descrito porque se refiere a un miembro de la corte imperial. Se plasmaba en ambos nombres el deseo de los padres en que su hijo fuera un personaje destacado. El último símbolo es el apellido propiamente dicho: «Sū»(蘇), el cual es muy popular en China. Por lo tanto la forma en la que el padre firmó originalmente fue «Guì Tíng Sū», o si se lee de derecha a izquierda como es costumbre en China sería: «Sū Tíng Guì [.... Queda claro entonces que el apellido solamente debió ser «Sū»(蘇) y el nombre Tíng Gui (廷贵). O sea [...] el hijo no debió llamarse Pedro Zulen, sino solamente Pedro Su. E «Len» no es más que un agregado que corresponde a la forma como el registrador entendió el primer nombre del padre: Tíng (廷). Al haberse castellanizado, la forma correcta de transcribirlo debió de haber sido «Suting» y no «Zulen», sin embargo el padre terminó aceptando esta transliteración, aunque siguió usando los dos caracteres originales para firmar (廷蘇) y antes de ellos el nombre que le quedaba fuera del nuevo apellido otorgado en el Perú (贵) [...] Con respecto al apellido «Sū» (蘇), si se le quiere buscar una significación específica, la misma puede ser traducida como «revivido desde la inconciencia», o sea «resucitado». O si se quiere, lo que es más común en español, el apellido «Resurrección». Pedro en chino se escribe Pèi Dé Luó (佩德罗), que es una adaptación sonora al sonido de la pronunciación en español. Por ello en el título de este artículo hemos consignado dicha información acompañando la traducción del apellido Zulen, puesto que, aunque como quedó claro, su apellido original fue «Sū» (蘇), sin embargo él siempre firmó aceptando la imposición de un nuevo apellido que se le otorgó en estas tierras a su padre: Zulen (o Sū Tíng: 蘇廷)". http://www.revistaoriental.com/pedro-zulen-2/

6 Según algunas versiones, otro caso fue el de Felipe Pinglo, cuyo apellido original pudo haber sido Ping Lo. Igualmente, su padre fue de origen asiático y su madre criolla.

7 Óscar, César, Carmen, Esther, Victoria, Elvira, Apolicarpio. 
En 1900, con once años de edad, Zulen ingresa al Colegio de Lima dirigido por el reconocido pedagogo Pedro A. Labarthe, en donde estudió también quien sería el importante dramaturgo que tempranamente se afincaría en España, Felipe Sassone, o el futuro arqueólogo Julio C. Tello, entre muchos personajes más. Desde temprano, nuestro filósofo destacaría por su inteligencia, facilidad para los idiomas y agudeza reflexiva.

El 14 de octubre de 1904, Zulen publicaría su primer artículo, "La religión y la ciencia a través de libros recientes", en el diario La Prensa. Desde entonces, sería un constante colaborador de diferentes diarios y revistas —alguna vez utilizó el seudónimo Neluz, su apellido al revés - incorporándose a ese torrente fundador del periodismo moderno peruano en el que destacaron numerosos intelectuales-periodistas. ${ }^{8}$ En los años 1906-1907 estudió en la Facultad de Ciencias Naturales y Matemáticas de la Universidad de San Marcos, dirigida en ese entonces por el destacado matemático Federico Villarreal. En el año 1908 sigue el curso Teorías analíticas fundamentales, dictado por el ingeniero Joaquín Capelo. Ahí se conocerían y estrecharían una gran amistad a pesar de la diferencia de edad. Capelo había nacido en Lima el 17 de junio de 1852, era, por lo tanto, 37 años mayor que Zulen.

\section{El maestro y amigo: Joaquín Capelo}

La relación amical que unió a Zulen con Capelo estuvo basada en temas de interés común, y su correspondencia así lo indica. Como informa Nadia Milushka López Soncco ${ }^{9}$, son 26 las cartas que se conocen cursadas entre estos dos pensadores. Es el más extenso intercambio epistolar que se registra en el Archivo Zulen, lo que nos da idea de la intensa vinculación que los unía. Este intercambio, según se puede registrar, inicia en 1916 (el año que Capelo renuncia a la presidencia de la Pro-Indígena) ${ }^{10}$ y concluye en 1923. Hasta aquella fecha, Capelo había sido varias cosas, pues era un hombre multifacético: ingeniero civil, maestro universitario, sociólogo, interesado en temas pedagógicos, defensor del indio, escritor, además de político. Pierolista él, se caracterizó por una crítica mordaz a los gobiernos civilistas, especialmente desde la labor parlamentaria que cumplió en tanto senador por Junín como miembro del Partido Demócrata — labor parlamentaria que concluiría en 1912-. Desde su curul parlamentaria fue un activo acusador de los abusos que los gamonales cometían en

8 Sobre la relación intelectuales y periodismo véase Osmar Gonzales Alvarado, Prensa escrita e intelectuales periodistas, 1895-1930, Universidad San Martín de Porres, Lima, 2010.

9 Nadia Milushka López Soncco, "Pedro Zulen y Joaquín Capelo: Una amistad Pro-Indígena” Pacarina del Sur [En línea], año 7, núm. 25, octubre-diciembre, 2015. Fuente: Pacarina del Sur - http://www.pacarinadelsur.com/ home/figuras-e-ideas/1219-pedro-zulen-y-joaquin-capelo-una-amistad-pro-indigena - Prohibida su reproducción sin citar el origen.

10 Capelo se aleja de la Pro-Indígena al parecer fastidiado por el escándalo protagonizado por Mayer, quien no tenía reparos en manifestar públicamente el amor que sentía por Zulen. 
contra de los indios. Fue autor de varios libros entre los que se pueden mencionar los cuatro volúmenes de Sociología de Lima (1895-1902), El problema nacional de la educación pública (1902)11 , La despoblación (1911) y, en Madrid, Los menguados (1912), publicado con el seudónimo Ma. Th. Ph., lo que lamentaría el propio Zulen (Jauja, 23 de junio de 1918), pues impedía identificar los elogios que el autor merecía.

Capelo aceptó la presidencia de la Pro-Indígena en 1909, cargo que ejerció hasta el año 1916, año en el que renunció. Luego del golpe en contra de Guillermo Billinghurst, perpetrado el 4 de febrero de 1914, Capelo sería ministro del dictador Óscar R. Benavides, aunque realizando una gestión sin mayor trascendencia y, posteriormente, tendría participación como funcionario en el segundo gobierno del civilista José Pardo y Barreda, su otrora adversario político. Producido el golpe de Estado de Augusto B. Leguía el 4 de julio de 1919, Capelo decide irse del país, primero a Estados Unidos y luego a Europa; moriría en París el 16 de noviembre de 1925, pocos meses después que su amigo Zulen.

Se puede decir que toda la correspondencia entre Zulen y Capelo está vertebrada por dos preocupaciones: por parte de Zulen, el debate de ideas y el análisis de la situación nacional; por parte de Capelo, la salud de su amigo, a quien le aconseja repetidamente que no se esfuerce, que primero se preocupe en estar bien y luego se dedique a sus intereses intelectuales y políticos; recomendaciones ante las cuales Zulen rezongaba (Jauja, 23 de junio de 1918). Sobre estos dos ejes escribirían acerca de los temas que los apasionaban.

En primer lugar, se debe tomar en cuenta que ambos experimentaban una gran insatisfacción con el orden oligárquico vigente. Capelo era un intelectual y político esencialmente crítico. Por ejemplo, le escribía a Zulen lo siguiente:" ... la nacionalidad no se ha formado, ni pueblo siquiera existe todavía, mucho menos nación [...] Un grupo de familias son los dueños absolutos de este país y lo serán muchos años todavía sin control alguno, están acostumbrados a triturar lo que se oponga a su camino" (Lima, 18 de julio de 1918). Zulen, por su parte, reflexionaba sobre la responsabilidad de la nueva generación: “... la generación que salve á este remedo de nación, tiene que ser una generación rebelde, altiva, amante de la verdad y de la justicia, con la función del patriotismo y aureola de las heroicidades [...] Una generación opacada y calculista, sin otra aspiración que el acomodo, jamás podrá salvar á este país" (Jauja, 23 de julio de 1918).

11 Augusto Castro Carpio, Una educación para re-crear el país, 1905-1930, Derrama Magisterial, Lima, 2013. La preocupación por el tema educativo fue un elemento de coincidencia entre Zulen y Capelo. No se puede dejar de mencionar que Zulen escribió cinco artículos sobre el tema, como "El problema nacional de la educación", que inició en La Prensa el 26 de marzo de 1909, y continuó los días 30 y 31 del mismo mes, y los días 1 y 3 de abril. También se debe mencionar su artículo "El pragmatismo en la educación" en El Hogary la Escuela - publicación de la escritora feminista Elvira García y García-, entre febrero y marzo de 1909. Asimismo, dejó inédito su "El movimiento contemporáneo de las ideas pedagógicas en el Perú".

\section{8/ RELUSTA DESSOCOLOOGÍA 26}


Otro tema presente en estas cartas es la vida política y su participación en ella. Mientras Zulen es activo y optimista, Capelo — alejado ya de la vida pública e incluso del propio país-, se muestra apático y pesimista. Son dos trayectorias personales que vuelan a distintas velocidades y en sentidos opuestos, pero que se intersectan, aunque en disímiles momentos de sus biografías. Es clara la diferencia cronológica y generacional que existe entre ellos. Capelo siempre anteponiendo la salud de su amigo; y Zulen confiando en la voluntad para actuar y superar cualquier dificultad. Ahí están sus artículos “Destruyamos el latifundio"(1915), "Socialismo y el problema social peruano" (1918), su “Discurso en la Plaza de la Concepción" (1918), y su“"Discurso a los indígenas de Marco" (1919) como testimonios de su mirada crítica y cada vez más radical sobre la realidad nacional. Aquí se anudan dos elementos importantes en el análisis de Zulen: por un lado, la necesidad de interesarse en la vida práctica y no solo especulativa; $y$, por otro lado, la concepción del ser humano como uno transformador, lo que lo colocaría en las reflexiones cada vez más cercanas a lo que llamaba revolución (no marxista), que más adelante analizo.

Un tercer tema o preocupación es el de la necesidad de conseguir trabajo por parte de Zulen, ante la cual Capelo puede hacer muy poco, en verdad. La reiteración de su situación económica nos recuerda a la de César Vallejo, aunque este era mucho más lúdico que nuestro filósofo, a quien Narda Henríquez ha descrito, con acierto, como "austero y disciplinado"12. Pero ambas experiencias, entre muchas otras, evidentemente, nos dejan ver con claridad la precariedad material en la que viven los pensadores y creadores en el Perú. Sin mecenas, sin instituciones académicas consolidadas, sin un Estado preocupado por sus carreras, los sujetos de ideas deben o están obligados a una indigna súplica por encontrar empleo y modo de subsistir pero sin dejar de cumplir con sus funciones en tanto pensadores o creadores. La inexistencia de un campo académico, el incipiente mercado para los sujetos de ideas y la profesionalización precaria de los mismos, en los inicios del siglo XX, no podían asegurar la reproducción social de los intelectuales, salvo por medio de acciones individuales y, también, de mucha suerte.

\section{La Asociación Pro-Indígena y Dora Mayer}

El año 1909 sería muy importante para Zulen por diferentes motivos. En ese año se trasladó a la Facultad de Letras, en la que permanecería hasta 1914, y también sería representante peruano de la Liga Inglesa de Educación, Ética y Moral, que presidía el filósofo James Ward. En dichos años afloraría su preocupación social. Participa-

12 Narda Henríquez, "Zulen, una travesía apasionante", Fénix núm. 42, 2000, 55. 
ría intensamente en el Centro Universitario, el que velaba por la formación de los estudiantes llevando a cabo conversatorios, y actividades en general, en su favor. Asimismo, propiciaba el interés de acercar las distintas ramas del conocimiento a los trabajadores, para lo cual se creó la Extensión Universitaria, en la que destacaría Óscar Miró Quesada (Racso) —otro miembro destacado del novecentismo— por su tarea de divulgación científica. Las conversaciones del Centro Universitario se iniciarían en el mes de abril de 1909 basadas en un reglamento elaborado por Zulen. Ahí se discutió primero sobre la educación del indio, y fue la ocasión en la que conocería a Dora Mayer.

Fue Zulen quien propuso, el 14 de octubre de 1909, la creación de un Patronato Nacional Pro-Indígena. El 20 de noviembre se instalaría ya la Asociación Pro-Indígena con la participación de destacados intelectuales, como Víctor Andrés Belaunde, José de la Riva Agüero, Alberto Ulloa Sotomayor, Alfredo González Prada, entre otros. ${ }^{13}$ En el reglamento, redactado por Zulen, se indica con claridad cuál es la misión de la novísima institución: “... la defensa de los intereses sociales de la raza indígena"14. Su presidente sería el ingeniero, senador, y ex profesor de Zulen, Joaquín Capelo, incansable acusador de las élites oligárquicas; Zulen sería el secretario general, y la responsable de publicaciones la escritora Dora Mayer. Los acompañarían en sus labores el escritor costumbrista Abelardo Gamarra y el historiador Rómulo Cúneo Vidal como vocales; el también historiador Vitaliano Berroa como tesorero, y el periodista italiano afincado en el Perú Emilio Sequi como bibliotecario ${ }^{15}$. La primera sesión de la Pro-Indígena se realizó el 30 de enero de 1910.

En su artículo "Centro Universitario" (La Prensa, 19 de abril de 1909), Zulen sostenía, como presidente de dicha agrupación universitaria, lo siguiente: "La conciencia nacional es más propia formándola con el indio que con elementos étnicos extraños". Se distanciaba así de los planteamientos de sus antecesores en dos aspectos: combatía el prejuicio racial y la solución de la inmigración de razas europeas (léase superiores) para la conformación de la nacionalidad ${ }^{16}$ en lo que la educación debería cumplir un

13 Wilfredo Kapsoli, El pensamiento de la Asociación Pro-Indígena, Debates Rurales 3, Centro Bartolomé de las Casas, Cusco, 1980.

14 La Asociación Pro-Indígena también se ocupó de los abusos cometidos contra las poblaciones amazónicas -Zulen fue parte de The Anti-Slavery and Aborigines Protection Society (1905)-, aunque en el caso del Putumayo, según Frederica Barclay Rey de Castro, su posición fue ambigua. Véase su artículo "La Asociación Pro Indígena y las atrocidades del Putumayo. Una misión auto restringida", Boletín Americanista, año LX.1, núm. 60, Barcelona, 2010.

15 Para el 15 de octubre de 1910 la composición había cambiado, ilustrándonos de la variedad de intelectuales que la conformaron: como bibliotecario figuraba Juan Bautista de Lavalle, como vocales Francisco Tudela y Varela, José de la Riva Agüero, Vitaliano Berroa, Víctor Andrés Belaunde, Felipe Barreda y Laos y Pedro Yrigoyen. Jorge Paredes Lara, op. cit., 91.

16 Joaquín Capelo compartía el pensamiento de Zulen. Llegando al final de la novela de crítica social, Los menguados, afirmaría: "La nacionalidad no puede conservarse sino con la virtud ciudadana y el patriotismo; esos dones no los trae la inmigración. En el mundo sólo tienen patria los que saben conservarla, los que merecen tenerla". Los menguados, Librería de Fernando Fé, Madrid, 218. 
papel esencial. ${ }^{17}$ Este es el marco conceptual con el que Zulen creaba la Pro-Indígena a sus 20 años de edad.

Carlos Arroyo Reyes sostiene acertadamente que la Asociación Pro-Indígena"fue la más importante de las instituciones que llegó a constituir el indigenismo peruano o acaso la única que alcanzó a desarrollarse como tal, sobre todo si se le compara con la Sociedad Amiga de los Indios (1867) o el Grupo Resurgimiento (1926-1927), que fueron experiencias un poco similares pero de muy corta duración".18 Como sostiene con acierto Katalin Jancsó, "La Asociación Pro-Indígena fue la institución más duradera del indigenismo peruano, por lo que podemos calificarla como la sociedad con mayor influencia, difusión y resonancia en todo el territorio de la república"19. Su importancia radica en que expresó "una corriente nacional y democrática a favor de los derechos de los indígenas", que "tenía un objetivo común pero no un pensamiento uniforme ${ }^{\prime \prime 20}$. Por su parte, Wilfredo Kapsoli destaca su crítica al gamonalismo, su oposición al latifundismo y a la voluntad de producir cambios en la vida de los indígenas dentro del orden burgués ${ }^{21}$.

En El Deber Pro-Indígena, Zulen escribiría varios artículos de denuncia -en contra del enganche, la práctica esclavitud a la que los grandes hacendados sometían al indígena, la conscripción vial, los bajos sueldos, el yanaconazgo, el enrolamiento forzoso en el ejército-, manteniendo siempre una actitud crítica, propugnando la defensa legal, pero, simultáneamente, en un proceso gradual, reconociendo a los indígenas como sujetos de derechos y deberes, es decir, como ciudadanos ${ }^{22}$.

Zulen conocía a Mayer gracias a los artículos que esta escribía para El Comercio, y supo reconocer en ellos una sensibilidad especial frente a los problemas nacionales, en particular la situación de los indígenas. Por ello, no dudó en invitarla a participar en la naciente asociación que tan destacado papel cumpliría en la denuncia de los abusos de los gamonales y de la perversión social que significaba el latifundio. Mayer no le falló a Zulen, por el contrario, fue el soporte fundamental de la Pro-Indígena; incluso financió personalmente la publicación El Deber Pro-Indígena (cuyo primer

17 La primera conversación sobre el tema educativo se realizó en el mes de marzo de 1909, los días 7, 14, 17 y 24. Un análisis más detenido se puede encontrar en: Joel Rojas Huaynates, "La educación y el racialismo en el discurso crítico de Pedro Zulen durante el debate en el Centro Universitario a inicios del siglo XX", Solar año 7, núm. 7, 2011.

18 Carlos Arroyo Reyes, Nuestros años diez. La Asociación Pro-Indígena, el levantamiento de Rumi-Maquiy el Incaísmo moderno, Libros en Red, Argentina, 2005, 12.

19 Katalin Jancsó, "Indigenismo político temprano en el Perú y la Asociación Pro-Indígena", Tesis doctoral, Szeged, 2009, 73.

20 Narda Henríquez, op. cit., 58.

21 Wilfredo Kapsoli, op. cit., 3.

22 Rubén Quiroz, Pablo Quintanilla, Joel Rojas, (Pedro Zulen. Escritos reunidos, op. cit.) han realizado la más amplia compilación de textos de Zulen, que nos da una visión bastante acabada del derrotero intelectual de este pensador. También puede consultarse, Joel Rojas Huaynates, Carlos Reyes Álvarez y Segundo Montoya Huamaní, En torno a Pedro Zulen, Universidad Nacional Mayor de San Marcos, Lima, 2014. 
número aparecería el 12 de octubre de 1912) que, editado en el Callao, donde residía Mayer, publicó 51 números (el último salió en diciembre de 1917). No es exagerado decir que el papel cumplido por la Pro-Indígena echó las bases de comprensión que tuvieron los miembros de la generación del Centenario sobre la explotación del indio.

El respeto de Zulen por Mayer fue retornado con una devoción enfermiza por parte de la escritora, protagonizando una de las historias más absurdas en las que estuvieron envueltas dos personalidades de las letras en el Perú.

Dora Mayer había nacido en Hamburgo el 12 de marzo de 1868, y llegaría al Perú cinco años después ${ }^{23}$. Era, por lo tanto, mayor que Zulen por 22 años. Aun así, no tuvo reparos en sentirse sentimentalmente atraída por el joven filósofo. Zulen siempre desmintió las versiones de Mayer sobre un supuesto idilio entre ellos, afirmando que solo era una historia inventada; el problema fue que Mayer no tuvo inconveniente en hacerla pública y publicar sus artículos como Dora Mayer de Zulen, como si estuvieran vinculados por matrimonio; incluso editaría, ya fallecido Zulen, un opúsculo titulado Zulen y yo. Testimonio de nuestro desposorio ofrecido a la humanidad (1925). Hermilio Valdizán definió como "psicosis erótica" al comportamiento de la escritora; mientras que Jorge Basadre señaló que le ocasionó un daño moral a su amigo y maestro ${ }^{24}$. Zulen desmintió en cuanta oportunidad tenía la versión de Mayer, y autorizaba a sus amigos a hacer lo mismo en su nombre. A Tello, por ejemplo, le escribiría: "Me han escrito de esa diciéndome que en la calle se dice que me he casado con Dora Mayer ¿Ha visto usted cosa igual? Supongo que usted no habrá dado crédito a semejante locura. Me dicen que ella se firma como si se hubiera realizado tal cosa, y que ha publicado un folleto con tal nombre. Usted comprenderá que esa no es sino una forma, para mí inesperada, de su antigua persecución. Lo autorizo para desmentir esto si se ofrece la oportunidad" (Cambridge, 29 de marzo de 1921). Se trata de una historia teñida de patético comportamiento.

No obstante, y yendo más allá de la anécdota, la relación entre Zulen y Mayer tuvo componentes importantes que nos ayudan a comprender el contexto histórico en el que vivieron. Por un lado, intelectual, pues ambos eran escritores y pensadores sociales destacados en el Perú oligárquico de inicios del siglo XX en el Perú. Coincidían en sus críticas a las élites oligárquicas y en la defensa del indio, así como en poner al

23 Puede consultarse Magdalena Chocano, Ideas políticas de Dora Mayer, Cendoc, Pontificia Universidad Católica del Perú, Lima, 1988; María Emma Manarelli, “La escritura femenina y la construcción del individuo a través de las Memorias de Dora Mayer (1868-1951)"en Ulrich Mücke y Marcel Velázquez (editores), Autobiografía del Perú republicano. Ensayos sobre historia y la narrativa del yo, Biblioteca Nacional del Perú, Lima, 2015; Margarita Zegarra Flórez, "Dora Mayer, los indígenas y la nación peruana a inicios del siglo XX", Anuario de Estudios Americanos vol. 66, núm. 1, 2009; Tirso Molinari y Susana Aldana, “El periplo intelectual de Dora Mayer: del indigenismo a su'lado oscuro"', Yuyaykusun núm. 2, 2009.

24 Jorge Basadre le rindió homenaje en "La herencia de Zulen", Boletín Bibliográfico núm. 2, 1925; y también en La vida y la historia, Banco Industrial del Perú, Lima, 1975. 
desnudo la precariedad de la República. Por otro lado, el sociológico, referido a las ubicaciones que cada uno ocupaba en la sociedad de su tiempo. Zulen, de origen asiático, un componente socio-cultural sobre el que recaía una serie de prejuicios, que fuera sojuzgado desde mediados del siglo XIX, y que era considerado como una raza inferior. Mayer, una alemana insertada en la vida peruana que, si bien provenía de una herencia valorada positivamente por el Perú oficial de su época, no terminaba de ser considerada peruana, a pesar de que vivía en el país desde los cinco años de edad; a ello habría que agregar el hecho de ser mujer en una sociedad misógina. Ni uno ni otra podían considerarse plenamente integrados a la vida social a pesar de exhibir inteligencia, talento y sensibilidad social más allá de lo común.

Es interesante destacar que Zulen nunca abordó directamente el tema de su herencia asiática. Incluso, cuando le propusieron ser Secretario Honorario de la Asociación de Comerciantes Chinos en el Perú se rehusó cortésmente aludiendo a no contar con el tiempo necesario que él debía dedicarle para cumplir bien con su labor $^{25}$. ¿Por qué esta - aparentemente al menos- desafección de Zulen con respecto a su herencia cultural? No es posible encontrar una respuesta certera en estos momentos. No hay rastros que nos indiquen cuál era su posición al respecto en sus artículos ni en sus cartas personales. Es posible suponer que atacando la situación del indio se refiriera, oblicuamente, a la de los asiáticos en el Perú.

Es frecuente encontrar en la correspondencia de Zulen sus reclamos y lamentaciones por falta de trabajo, de dinero y de ayuda en general. Como ha señalado Narda Henríquez, Zulen experimentó el "[v]ivir entre dos mundos, pero también sentirse en los márgenes"26. Mayer, por su parte, inquiría por qué no se la consideraba una escritora peruana. En una carta dirigida a Luis Varela y Orbegoso, Clovis, hace explícita su desazón: "Es verdad que soy de puro origen alemán; pero estoy segura que si de casualidad hubiese nacido en el suelo peruano, mucha más disposición habría para reconocerme peruana. Sin embargo, ¿qué importa la casualidad del lugar del nacimiento al lado de toda una vida en que se ha respirado el ambiente de aquí, y de todo un pensamiento concretado a los problemas locales, y de todo un corazón arraigado en esta tierra? Si tanto importara el sitio del nacimiento, el niño nacido en una travesía por el mar no podría tener patria, y ya vendrán los tiempos en que los niños nazcan en el aire, en el aeroplano" ${ }^{\prime 27}$. Esta exterioridad y al mismo tiempo integración parcial

25 Lima, 18 de julio de 1913. Archivo Zulen, Biblioteca Nacional del Perú.

26 N. Henríquez, op. cit., 61.

27 "El caso de Dora Mayer", en "La hora actual", El Comercio, 22 de marzo de 1924. Clovis responde: "La obra toda de Dora Mayer es una obra genuinamente peruana, y quien ha vivido, como ella, toda su vida en un país, lo ha comprendido y lo ha amado como el mejor y el más sincero de sus hijos, no puede ser de otra nación y de otra patria.///Peruana por el corazón, peruana por su obra, peruana por su vida, Dora Mayer es escritora del Perú y de las que más lo honran y lo enaltecen". 
o subordinada a la sociedad los hicieron especialmente sensibles a la situación de los indígenas, partes fundamentales de la nacionalidad, pero simultáneamente no reconocidos como ciudadanos. De esta manera, las reflexiones intelectuales de Zulen y Mayer encuentran sus bases más profundas en sus propias biografías.

\section{Dos sensibilidades especiales: Pedro Zulen y José María Eguren}

En la revista Ilustración Peruana, Zulen publicó el que sería uno de los primeros reconocimientos al poeta José María Eguren: “Un neo-simbolismo poético Apuntaciones sobre José María Eguren y sus poesías", aparecido el 22 de noviembre de 1911. Ahí afirma: "... la musa de José María Eguren vaga allí entre cielos de fantasía, vapores misteriosos y sueños de desconocida abstracción".

La relación con el poeta Eguren fue sumamente cercana, basada su amistad en aspectos que guardaban similitudes como, por ejemplo, una especial sensibilidad por la cultura, los libros, la poesía, pues Zulen también versaba ${ }^{28}$, y con un brío que el propio Eguren admiraba. En la correspondencia mantenida por ambos hombres de letras abundan detalles no solo sobre autores y libros, sino también sobre el papel que cada uno jugó a favor del otro para difundir sus creaciones. Otra similitud que los acercaba era la frágil salud que los hacía pasar en numerosas ocasiones por agudas crisis. Sus organismos débiles, al parecer, estaban en relación directa con sus finos espíritus. También, de alguna manera, acercaba a Zulen y Eguren una cierta marginación de lo que podemos Ilamar la cultura oficial y de la sociedad aceptada. Zulen por provenir de un sector socio-cultural estigmatizado (el asiático), además de ser pobre; y Eguren, quien a pesar de ser parte de una familia notable ${ }^{29}$, no era incorporado plenamente por su carácter tímido e inhibido, además de por su poesía absolutamente inédita e incomprensible para los cánones de la época. Solo algunos la comprendieron, como el propio Zulen, tanto así que en 1924 editó una selección de las poesías de su amigo en el que sería el último número del Boletín Bibliográfico que él dirigió, con una nota de Enrique Bustamante y Ballivián, en la que señala, entre otras cosas, lo siguiente: "Agotadas las ediciones de Simbólicas, 1911, y La Canción de las Figuras 1916, y hechos cada vez más raros los ejemplares de estos libros, por el interés que la crítica extranjera, europea y americana, ha

28 Póstumamente, se editaron sus poesías bajo el título El olmo incierto de la nevada, con introducción de Dora Mayer.

29 José María pertenece a la tercera generación de los Eguren en el Perú, familia que adquirió importancia y estatus desde pocos años antes de los inicios de la República. Sobre dicha familia pueden consultarse los artículos de Isabel Cristina López Eguren, "José María Eguren y su abuelo al servicio del rey de España", Expreso, 5 de mayo de 2015; "La familia Eguren en el Perú: los hermanos del poeta", Yuyaykusun núm. 8, noviembre de 2015; y“José María Eguren y Cáceda, el padre del poeta", http://www.librosperuanos.com/autores/articulo/00000002357/ Eguren-y-Caceda-el-padre-del-poeta, febrero de 2016.

\section{4/ RELUSTA DE SOCOLOOGIIA 26}


tenido en estudiar la original y profunda poesía de Eguren, hemos considerado un deber bibliográfico la publicación, en este Boletín, de Simbólicas y de algunos poemas de La Canción de las Figuras y de Sombra, libro inédito, agregando algunas composiciones sueltas. La selección ha sido hecha por Pedro S. Zulen, Director de este Boletín, uno de los mejores amigos y más entusiastas admiradores del originalísimo poeta" ${ }^{\prime 30}$.

Como solía ocurrir con el poeta, Zulen no podía tratarlo si no con dulce amistad, después de todo, recordemos, Valdelomar había descrito a Eguren como "el mejor amigo". Actitud de Zulen que no ocurría con otros personajes que, aun cuando cercanos a él, no escapaban de sus reconvenciones o arrebatos, como se observa en su correspondencia ${ }^{31}$ con Tello, por ejemplo, en donde podemos conocer sus comentarios sobre Belaunde; también se puede mencionar su polémica con Mariátegui y su llamada de atención a este conminándolo a leer mejor al filósofo James Bryce. A diferencia de Eguren, Zulen, al parecer, no era dueño de un carácter afable. Su circunspección ante la difícil vida que le tocó llevar, su seriedad para seguir sus estudios y proyectos académicos, quizás lo volvieron poco refractario a las desviaciones de carácter, a lo que consideraba debilidades o, incluso, a apreciaciones que entendía eran erradas. En cierto modo, se parecía en algo al temperamento de Riva Agüero - precozmente maduro-, de quien admiraba su enorme talento intelectual ${ }^{32}$. Esto lo diferenciaba de Mariátegui, poseedor de una gran capacidad de comprensión y empatía, aunque ello no obstó para que fueran amigos y que, en los últimos años de vida de Zulen, sus ideas los acercaran aun más, teniendo ambos como horizonte social y ético al socialismo, aun cada uno tiñera su utopía con sus particulares coloraciones: Mariátegui, marxista; Zulen, adscripto al socialismo-parlamentario.

Curiosamente, Zulen, Eguren y Mariátegui adolecían de mala salud. Zulen y Mariátegui murieron a los 35 y 36 años de edad respectivamente, demasiados jóvenes considerando el legado que forjaron. Si bien Eguren tuvo una vida más larga —-murió a los 61 años de edad - , su salud siempre estuvo resquebrajada. Considero que tanto Zulen como Mariátegui fueron intuitivamente conscientes de los riesgos de sus frágiles organismos (en algún momento Zulen escribiría "la vida es corta"), y que por ello aceleraron el fragor de su creatividad, para bien de la cultura peruana.

30 Enrique Bustamante y Ballivián, "José M. Eguren: sus mejores poesías. De 'Simbólicas' (Lima, 1911)", en Boletín Bibliográfico, Vol. I, Núm. 15, diciembre 1924. http://sisbib.unmsm.edu.pe/exposiciones/pzulen/personajes/ eguren.htm

31 El intercambio epistolar entre Pedro Zulen y José María Eguren se puede consultar en Ricardo Silva Santisteban, José María Eguren. Obras Completas de Eguren, Biblioteca Clásicos del Perú/7, Banco de Crédito del Perú, Lima, 1997.

32 Véase "Los estudios de Riva-Agüero" publicado en tres partes en la revista Ilustración Peruana: 15 de febrero, 22 de febrero y 15 de marzo de 1911 


\section{Disputa y acercamiento con José Carlos Mariátegui. Distintas formas de radicalidad}

Desde 1912 hasta el año siguiente, Zulen trabajaría como auxiliar en la biblioteca de la Universidad de San Marcos, a la que volvería en los momentos finales de su vida. Durante los años 1914 y 1915 seguiría estudios en la Facultad de Jurisprudencia y Ciencia Política. En 1914 funda la Asociación Ethos con el propósito de impulsar una "cultura ética". En el año siguiente polemizaría con Juan Croniqueur (seudónimo utilizado por Mariátegui) quien publicó su comentario sobre la obra de James Bryce, La América del Sud, que apareció en La Prensa.Zulen firmaría como Z el artículo aparecido en La Crónica, y sería muy agresivo en su crítica. Lo califica de "bebe con pretensiones de sensatez". A su vez, Mariátegui retrucaría con adjetivos como siamesco, rastacuero y chabacano. Zulen no se quedaría callado y enviaría una carta en la que afirma "basta un vercesito o una croniquita de pacotilla, para hacer reputaciones". No obstante, las rivalidades fueron limadas y ambos intelectuales establecerían una cordial amistad. Mariátegui en su 7 ensayos describiría positivamente la labor de Zulen en la Pro-Indígena, aunque, como sabemos, confiriéndole un sentido fundamentalmente filantrópico. Sin embargo, como recuerda, Song No, Mariátegui, en su artículo publicado en Mundial el 5 de febrero de 1925 (E.D. Morel-Pedro S. Zulen, vidas paralelas") había ofrecido "unos comentarios más favorables en Mundial, justo después de la muerte de Zulen, estimando su "profunda filiación democrática" y subrayando que, en sus últimos años, "madura en Zulen, lentamente, la fe en el socialismo"33.

Considero que, en buena parte, la posición de Mariátegui sobre el tema indígena estuvo basada en el conocimiento que adquirió sobre la situación del indio gracias a la labor de denuncia de la Pro-Indígena. Coincidente en este punto con Zulen, luego cada uno tomaría una ruta distinta. Ambos representan momentos importantes en la toma de conciencia sobre el llamado "problema del indio". Pero habían otros elementos que los identificaban, como considerar al ser humano como siempre capaz de modificar sus circunstancias (y vaya que cada uno lo sabía por experiencia propia) ${ }^{34}$; la centralidad que otorgaban al papel de la cultura, del arte y de la creatividad en todas sus formas; un profundo sentido ético de la vida; la convicción de que la nacionalidad era un proyecto mas no una realidad, $y$, finalmente, que era necesario cambiar el orden social y político.

33 Song No, "Entre el idealismo práctico y el activismo filosófico: La doble vida de Pedro Zulen", Solar año 2, núm. 2, 2006, 74 .

34 Como sostiene Segundo Montoya, sea desde la"perseverancia zuleniana" o de la "agonía mariateguiana". https:// pedrozulen.wordpress.com/2015/12/19/vidas-paralelas-zulen-y-mariategui-por-segundo-montoya/ 
Terminada la experiencia de la Asociación Pro-Indígena, Zulen continuó con su labor a favor de los habitantes de los Andes, en lo que coincide con Mariátegui. Como relata Katalin Jancsó: "En estos años Zulen no se olvida de su labor indigenista. Colabora con el Comité Central Pro-Derecho Indígena Tahuantinsuyo, institución que se funda en 1919 gracias a la iniciativa de ex delegados de la API, líderes indígenas y obreros anarcosindicalistas. Zulen, Mayer, Francisco Chuquihuanca Ayulo y otros ex miembros de la API también apoyan las actividades del comité. En 1921 se organiza el Primer Congreso Indígena Tahuantinsuyo, en el que Zulen no puede participar porque en esos momentos reside en los Estados Unidos. Es en 1923, en el tercer congreso, cuando puede al fin asistir y es allí donde conoce al joven José Carlos Mariátegui (recién regresado de Europa), a quien empieza a visitar en su casa y con el que en poco tiempo traba amistad. Mariátegui así recuerda su encuentro: "Recuerdo nuestro encuentro en el Tercer Congreso Indígena, hace un año. El estrado y las primeras bancas de la sala de la Federación de Estudiantes estaban ocupadas por una policroma multitud indígena. En las bancas atrás, nos sentábamos los dos únicos espectadores de la Asamblea. Estos dos únicos espectadores éramos Zulen y yo. A nadie más había atraído este debate. Nuestro diálogo de esa noche aproximó definitivamente nuestros espíritus" ${ }^{\prime \prime 35}$.

Resulta interesante establecer algunas comparaciones entre estos dos pensadores que se dedicaron al periodismo y lo utilizaron como una plataforma para exponer sus análisis de la cultura y la vida social peruana.

En efecto, como sucede con Mariátegui, la mayor parte de la obra de Zulen transcurre por las páginas del periodismo. Salvo sus dos tesis filosóficas, fue un asiduo colaborador (e incluso fundador) de diarios y revistas. En dichos artículos abordó diferentes temas como la situación del indio, la educación, la religión, la literatura, la producción libresca, temas filosóficos, y otros ${ }^{36}$. Es decir, prácticamente los mismos tópicos que preocuparon a Mariátegui. Pero hay diferencias que deseo exponer.

35 Katalin Jancsó, op. cit., 87. Continúa Mariátegui: "Y recuerdo otro encuentro más emocionado todavía: el encuentro de Pedro S. Zulen y de Ezequiel Urviola, organizador y delegado de las federaciones indígenas del Cuzco, en mi casa, hace tres meses. Zulen y Urviola se complacieron recíprocamente de conocerse. "El problema indígena —dijo Zulen - es el único problema del Perú". Zulen y Urviola no volvieron a verse. Ambos han muerto en el mismo día. Ambos, el intelectual erudito y universitario y el agitador oscuro, parecen haber tenido una misma muerte y un mismo sino". José Carlos Mariátegui, "E. D. Morel-Pedro S. Zulen", Mundial, Lima, 6 de febrero de 1925. Solo una precisión: las reuniones a las que se refiere Mariátegui no ocurrieron en su casa de Washington Izquierda, a la que se mudaría recién en 1925, cuando Zulen ya había muerto.

36 Aunque cada uno mostró intereses por otros temas. Zulen, por ejemplo, escribió también sobre psicología, lógica, microbiología, espiritismo e, incluso, extraterrestres. Mariátegui, por su parte, abordaría temas como el psicoanálisis, el debate ideológico, más precisamente el marxismo, la realidad internacional, sin mencionar sus crónicas sobre carreras de caballos, vuelos en aeroplanos, y aspectos diversos de la vida social. 
Lo más evidente es que Zulen fue un académico puro, producto de todas las etapas de la educación formal; Mariátegui, por el contrario, fue un pensador social autodidacta formado desde su inteligencia y sensibilidad a partir de la voluntad y experiencias vitales significativas.

Zulen se interesó desde un inicio por los temas sociales, a contrapelo de Mariátegui quien inició su carrera como periodista escribiendo crónicas sociales de tono frívolo. Por otro lado, nuestro filósofo mantuvo siempre un tono serio y reflexivo que incluso parecía de una persona de mayor edad; mientras que Mariátegui publicaba notas con un tono iconoclasta y de humor. En otras palabras, Zulen se dedicó a temas de importancia aun antes de sus viajes a Estados Unidos; mientras que el Amauta los haría a plenitud luego de su regreso de su estancia en Europa en el año 1923. Desde esa fecha hasta 1930 produciría una gran cantidad de artículos y de gran trascendencia sobre la realidad nacional y de carácter doctrinario, como no lo hizo Zulen, quien tampoco se comprometió explícitamente con alguna corriente ideológica ni mucho menos política. Quizás ello le impidió exponer una visión integral del Perú en un momento de efervescencia doctrinaria. Si bien denunció el orden de dominación feudal en contra del indio, en sus textos no aparecen personajes concretos de la vida política peruana, es decir, el poder no tiene rostro, lo que no deja de llamar la atención. Zulen no era un analista de coyuntura; sus reflexiones estaban enfocadas en los trazos generales y más profundos, no en los episódicos. Esto le quitaba fuerza a sus denuncias políticas, pero al mismo tiempo contribuirían a explicar las bases del orden feudal. La impronta del filósofo se advierte fácilmente en sus escritos. Pero más allá de estas diferencias, a ambos, a Zulen y Mariátegui, hay que comprenderlos como partes de una línea histórica de pensamiento en el Perú.

\section{Las cartas con Julio C. Tello}

Ya he mencionado que su condición social de marginación relativa por su origen paterno fue un factor fundamental en la vida de Zulen. De tal modo, ejerció una influencia que aun cuando había conseguido logros que muy pocos peruanos habían sido capaces de alcanzar hasta entonces -estudiar filosofía en Harvard y ser reconocido por sectores de la comunidad académica estadounidense: su correspondencia con Bertrand Russell es un detalle que no debe ser obviado- el Perú oficial siempre fue reacio a reconocerle el lugar que merecía. La academia peruana, especialmente limeña, lo contuvo en sus márgenes, salvo excepciones; algo parecido a lo ocurrido con Tello, amigo de Zulen y nueve años mayor que él, llamado con cierto desdén como el Cholo Tello, quien debió bregar para obtener el reconocimiento que anhelaba. A diferencia de Zulen, Tello tuvo más vida para

\section{8/ REEUSTA DE SOCODLOGíA 26}


lograrlo (murió en 1947, a los 67 años de edad). Habían, pues, experiencias vitales que los acercaban.

Como sostienen Miguel Ángel del Castillo y María Moscoso Carbaja ${ }^{37}$, Tello y Zulen se conocerían, al parecer, en 1913, luego de que aquel regresara al Perú después de haber realizado sus estudios de posgrado en la Universidad de Harvard entre 1909 y 1911, gracias a una beca concedida por el gobierno de Augusto B. Leguía. Allí conoció a maestros como Aleš Hrdlička y Franz Boas. En 1909 obtuvo la maestría en Artes y dos años después en Antropología. Tello tuvo el privilegio de ser el primer peruano en obtener dicho grado académico en tan prestigiada universidad. Gracias a su inteligencia y méritos, obtuvo una nueva beca, esta vez para Londres, en donde participó en el XVIII Congreso Internacional de Americanistas, en 1911, y otra para continuar con sus estudios en el Seminario de Antropología de la Universidad de Berlín el año siguiente. En 1913 retornó al Perú realizando investigaciones con Hrdlička en los valles de la costa central. Dirigió la sección arqueológica del Museo de Historia Nacional hasta $1915^{38}$. Dos años después sería elegido diputado, como representante del Partido Nacional Democrático fundado por José de la Riva Agüero, por la provincia de Huarochirí, cargo en el que permaneció 12 años, entre 1917 y 1929. Tello estudió con detenimiento la cultura Chavín (1919), y esas investigaciones dieron pie para sus tesis autoctonistas. Los estudios arqueológicos de Tello abrirían nuevos horizontes en la comprensión de nuestro pasado. De esta manera, el nexo de una preocupación intelectual unía a Tello con Zulen: la vida del indio en la historia y en la actualidad. En una carta, Zulen le escribe a Tello: "En el correo pasado recibí su Introducción a la historia antigua del Perú, trabajo que me ha agradado mucho y que honra a la ciencia y al país" (Cambridge, 3 de febrero de 1922). Es innegable que estaba al tanto de la producción intelectual de su amigo.

Por otro lado, el hecho de haber estudiado ambos en Harvard los llevaría a establecer comparaciones con San Marcos y la realidad universitaria estadounidense. A pesar de estos elementos comunes, Zulen criticó con cierta displicencia el proyecto de ley universitaria presentado por Tello, generando un resentimiento por parte de éste, que al parecer no pudo ser superado totalmente. Asimismo, Zulen sería ácido con respecto a Víctor Andrés Belaunde. Luego de ir a una conferencia de este sobre poesía hispanoamericana diría "¿Qué vaciedad, Dios mío!" (Cambridge, 29 de julio de $1920)^{39}$. Tello también tendría sus críticas sobre Belaunde al igual que con Manuel

37 Miguel Ángel del Castillo y María Moscoso "El chino y el Indio: Pedro S. Zulen y Julio C. Tello, una amistad del novecientos a través de su correspondencia, 1914-1922", Arqueología y Sociedad núm. 14, 2002.

38 Ese mismo año, Zulen recomienda a los delegados de la Asociación Pro-Indígena a Julio C. Tello para que lo apoyen en las investigaciones que se prestaba realizar en Arequipa, Puno y Cusco (Lima, 21 de abril de 1915).

39 No sabemos el origen del distanciamiento entre Zulen y Belaunde luego de haber coincidido en la Pro-Indígena. Quizás fueron desavenencias al interior de esa asociación. 
Vicente Villarán —al que Zulen defendería ${ }^{40}$ - quien después sería el que le diera la oportunidad de regresar al Perú con un trabajo en la Biblioteca de la Universidad.

En las cartas intercambiadas entre Tello y Zulen se puede observar cómo los amigos de éste actuaron rápidamente para sacarlo de la cárcel en 1919, luego de su discurso en el distrito de Marco, Jauja. Asimismo, la urgencia por encontrar trabajo remunerado, que incluso adquiere un tono dramático: "Si yo no tuviera a mi padre enfermo y a mi familia en necesidad, no estaría rogando y a personas que parece nunca hubieran estado en necesidades" (Cambridge, 17 de enero de 1922). 0 estas líneas: "Hace cuatro días recibí carta de mi familia, de Lima, donde me anuncian que mi madre está tan mal que es posible que no la encuentre ya el día que vuelva" (Cambridge, 2 de junio de 1922). Por ello, Zulen gestiona y pide a su amigo que lo apoye para que pueda cobrar lo que se le adeuda primero para pagar sus propias deudas y, luego, para retornar a Lima.

\section{La enfermedad y la política}

En 1915 Zulen funda y financia la publicación La Autonomía ${ }^{41}$, que apareció por primera vez el 21 de agosto y enarbolaba la creación de la Liga Descentralista del Movimiento Regionalista del Sur. 1916 sería un año de viajes: Chile, Argentina y Estados Unidos, específicamente a la Universidad de Harvard, pero debido a su mala salud - ya estaba incubada en su organismo la tuberculosis—, debió regresar al Perú. Por dicha razón se trasladó a vivir a Chosica, pero manteniendo el deseo de trasladarse a Jauja, en donde viviría entre 1918 y 1919. El 9 de julio de 1918 denuncia la ficción que es nuestra República. La publicación La Evolución de Huancayo transcribiría su discurso al día siguiente. En junio de 1919 se presenta como candidato a diputado suplente (de Capelo precisamente) por Jauja, pero sin éxito. Por motivo del durísimo discurso en Marco, Zulen sería detenido por cinco días, acusado de bolchevique y maximalista. Como se observa, el filósofo Zulen no desdeñaba la participación política, era expresión de su proceso de radicalización conceptual.

En Zulen ya está presente la idea de que acabar con el sistema de expoliación del indio necesitaba de un cambio fundamental basado en la propia participación indígena. Sin embargo, paralelamente a esta postura radical se encuentra su pretensión de obtener los votos necesarios que lo eligieran congresista suplente ${ }^{42}$. No

\footnotetext{
40 Hay que señalar también que Zulen reconocería la importancia de las tesis de Villarán sobre el tema educativo, proponiendo una educación práctica.

41 Como bien destaca Narda Henríquez: “[...] la elección del nombre La Autonomía tiene un gran simbolismo. Desde muy joven Zulen alude al "self-government" como expresión de la necesidad de los derechos ciudadanos y las virtudes cívicas...", op. cit., 59.

42 En la publicación El Eco de Junín (1 de marzo de 1919), apareció una hoja suelta de propaganda a la postulación
}

\section{0/ REEUSTA DE SOCDOLOGíA 26}


debe llamar la atención dicha ambigüedad ni la mencionada pretensión, pues no era un revolucionario marxista, y su crítica la conducía aún por los caminos esbozados por los novecentistas aun cuando avanzaba algunos pasos colocándose en el lugar de los campesino-indígenas para agitar sus denuncias contra el gamonalismo. Tampoco debe sorprender su postulación al Parlamento, pues la experiencia de la Pro-Indígena estuvo marcada por la necesidad de impulsar una legislación que cautelara los derechos del habitante andino, ¿y qué mejor lugar para producir esas leyes que el Congreso? No hay que olvidar que amigos y contemporáneos de Zulen sí habían logrado ser elegidos como representantes: Encinas por Puno, Tello por Huarochirí, Capelo por Jauja, Valdelomar murió luego de ser elegido como diputado regional por Ica en 1919 en los inicios del leguiísmo. Todos ellos habían movilizado su pluma y su voz en defensa del indio histórico y del presente. Un trayecto que Zulen pretendió replicar. Fue, pues, un filósofo que reflexionaba sobre asuntos abstractos (el 12 de noviembre de 1919 obtuvo el bachillerato en Letras con su tesis sobre Henry Bergson titulada "La filosofía de lo inexpresable. Bosquejo de una interpretación y una crítica de la filosofía de Bergson", que publicaría el año siguiente), y al mismo tiempo un pensador social que empezaba a fustigar el orden de dominación social.

Zulen como filósofo no rechazaba la actividad práctica y el compromiso político, como ya hemos visto. De primera impresión, se podría suponer que un filósofo de su envergadura vería con distancia e incluso con desdén el participar activamente en la lucha política, pero ello no fue así en su caso. No es difícil imaginar lo destacado que hubiera sido Zulen como congresista, con ideas claras, con sensibilidad social, con su sentido del deber y del trabajo, así como exhibiendo una distancia crítica del orden establecido, características que lo hubieran convertido en temible fustigador para las élites oligárquicas. Como le recomendó alguna vez José Enrique Rodó a Francisco García Calderón: seamos ciudadanos siempre, y de vez en cuando demos una vuelta por el ágora. Zulen trató de cumplir dicho precepto.

En agosto de 1920 Zulen está de vuelta en la Universidad de Harvard gracias a una beca del Estado peruano. Ahí estudió psicología y filosofía, y siguió estudios de bibliotecología, tal como se lo hace saber al entonces Rector de San Marcos, el destacado jurisconsulto Manuel Vicente Villarán, pero la pobreza y la mala salud lo aquejan y escribe reiteradamente a sus conocidos y amigos pidiendo apoyo, trabajo. Zulen retorna al Perú en el mes de octubre de 1922. En 1923 Villarán lo ubica en el área de catalogación de la biblioteca universitaria con un sueldo de Lp. 25 mensuales. Rápidamente, el 24 de marzo, asume la dirección interina de la biblioteca. Su labor

de Zulen, que luego reproduce La Evolución de Huancayo (8 de marzo de 1919). 
como bibliotecario es fecunda: publica el Boletín Bibliográfico (sacando a la luz 15 números entre julio de 1923 y diciembre de 1924$)^{43}$, adquiere libros científicos, ordena la biblioteca de modo profesional, instaura el servicio dominical. El 12 de agosto de 1924 ya es bibliotecario titular. Lleva a trabajar con él al joven historiador Jorge Basadre, quien laboraba en la Biblioteca Nacional como auxiliar. Este aprendizaje sería fundamental para el futuro director y reconstructor de la Biblioteca Nacional luego del incendio de 1943. Casi simultáneamente, Zulen es designado catedrático libre de Psicología y Lógica. El 16 de setiembre sustentó su tesis doctoral en filosofía:"Del neohegelianismo al neorrealismo. Estudio de las corrientes filosóficas en Inglaterra y los Estados Unidos desde la introducción de Hegel hasta la actual reacción neorrealista" ${ }^{\prime 4}$.

Pocos meses después, el 27 de enero, Zulen moriría en su casa de llave 114 en Lima a consecuencia de la tuberculosis.

\section{El legado de Pedro Zulen}

Zulen murió cuando se acercaba al socialismo, abandonando o superando la visión paternalista y humanitaria que observó durante el tiempo que dirigió la Pro-Indígena. De cierta manera trágica, Zulen repitió el camino seguido por Valdelomar, quien también, pocos años previos a su muerte, su dandismo literario estaba siendo desplazado por un pensamiento social crítico que identificaba al gamonalismo como uno de los males principales del país y que explicaba la postración e ignorancia del indio peruano. Pero su muerte, en 1919, cuando solo contaba con 31 años de edad, interrumpió un proceso intelectual e ideológico que posiblemente se hubiera radicalizado más incluso. Similar a lo ocurrido con Zulen.

Factores biográficos, intelectuales y sociales se conjugaron para producir el resultado de un Zulen que cada vez más tomaba mayor distancia de lo establecido.

En términos intelectuales, Zulen fue un lector voraz que permanentemente actualizaba sus conocimientos y expandía sus intereses hacia temas incluso incomprendidos por los demás. A ello debe sumarse algo no despreciable en cuanto a la experiencia de los individuos, en este caso el intelectual, cual es el de vivir y estudiar en el extranjero, lo que le permite obtener una mirada diferente sobre los problemas nacionales, incorporando nuevas reflexiones, lecturas, puntos de vista. El retorno posibilita la constatación de lo aprendido y lo vivido con la propia realidad, lo que genera

43 Un excelente balance del Boletín Bibliográfico se puede encontrar en Alberto Loza Nehmad, "Y el claustro de abrió al siglo: Pedro Zulen y el Boletín Bibliográfico de la Biblioteca de San Marcos (1923-1924)", Letras vol. 77, núms. 111-112, 2006.

44 Un análisis detallado de esta tesis en Martha Zolezzi, “Pedro S. Zulen (1889-1925)”, en María Luisa Rivara de Tuesta (coordinadora), La intelectualidad peruana del siglo XX ante la condición humana, tomo I, Lima, 2004. 
a su vez nuevos conocimientos y planteamientos de interpretación; es el momento de reformulaciones, de discernir qué ideas son útiles y cuáles no.

Al mismo tiempo, es necesario señalar que Zulen era también un intelectual que reflexionaba sobre su función social. Con gran agudeza, comentando los trabajos de Riva Agüero (Ilustración Peruana, 15 de febrero de 1911), a quien define como escritor-político, sostiene que para escribir El carácter de la literatura del Perú independiente - tesis de Riva Agüero de 1905-, "habría sido necesario estudiar las condiciones morales, intelectuales y hasta filosóficas en que cada literato, prosador o poeta, novelador o crítico, escritor u orador, se desarrolló, cuál fue el ambiente educativo que lo rodeó, el estado social de su tiempo, el trato que frecuentaba". Y añade: "La crítica debe ser psicológica, y el carácter de una literatura debe implicar a un mismo tiempo el de los que la han producido". En gran medida, se adelanta a la teoría de las mediaciones de Jean Paul Sartre para estudiar a los intelectuales ${ }^{45}$, y en menor grado a lo que Pierre Bourdieu llamaría sociología crítica de los intelectuales ${ }^{46}$. Es una lástima que Zulen no haya podido llevar a cabo — si es que se lo propuso alguna vez- un estudio sobre los intelectuales desde su propia propuesta teórica. En otras palabras, Zulen contaba con todas las capacidades para constituirse en un intelectual estudioso de los intelectuales. Sus artículos bosquejando análisis sobre la producción intelectual del Perú nos dan una idea de su interés y enfoque. Así tenemos, por ejemplo, su artículo "El Perú intelectual en 1908" ( $L a$ Prensa, 1 de enero de 1909) en el que revisa los principales títulos y autores del año con un sesgo crítico bien informado, y establece su idea de lo que debe ser la responsabilidad del intelectual: "Aquí lo que necesitamos son hombres de acción, caracteres que se sustraigan a la sugestión del medio, que no sean simples críticos aislados, que sean capaces de llevar a la práctica con interés altruista sus ideales y teorías; que no nos vengan a predicar moralidad, los que no son morales". Dos cosas fundamentales exige Zulen al sujeto de ideas: participación activa en la vida social y sentido de la moral.

Lo anterior encaja perfectamente con su convicción de que la moral es la vía para regenerar la vida social y las instituciones ligado con la educación y a su concepción sobre el ser humano. Así, expresa su visión integral sobre el tema, anunciando las ideas de Encinas: "La escuela, el colegio, la universidad, los institutos técnicos, el taller, el libro, la revista, el periódico, el buen ejemplo en el hogar y en el medio social, la naturaleza del medio físico, serán todos los manantiales de que se aproveche la educación pragmática, para que por su eficacia el hombre se eduque sobre todo a la edad de la razón, por sí mismo, para que pueda él efectuar la cultura continua de

45 Jean Paul Sartre, Crítica de la razón dialéctica, Editorial Losada, Buenos Aires, 1963.

46 Pierre Bourdieu, Campo de poder, campo intelectual, Editorial Montressor, Tucumán, 2002. 
su conciencia moral" ("El pragmatismo en la Educación", El Hogar y la Escuela núm. 5, de marzo de 1909). Según Saby Lazarte, Zulen tuvo un énfasis humanista: "cómo debe ser el hombre y cuáles deben ser sus cualidades"47: "Los males de que adolece una colectividad tienen que reflejarse necesariamente en todas sus instituciones. Resolver el problema educativo es resolver el problema social. Y ¿qué es la cuestión social, sino una cuestión moral?" ("Educación y crítica. II", Contemporáneos núm. 8, 28 de julio de 1909). Entre esas cualidades destaca una: la perseverancia, la que "los hombres que llevan en sí el sentimiento de la acción" ("Boceto de la perseverancia", El Deber Pro-Indígena núm. 7, 7 de abril de 1913).

La perseverancia, además, es importante más allá de sus resultados "porque sirve de escuela viva, de lección educadora a los demás hombres, estimulándolos hacia la práctica, hacia la acción, hacia la vida misma" (op. cit.). La perseverancia es un valor de las personas. Gracias a ella pueden cambiar sus circunstancias, no es solo un maximizador de su medio. Además, Zulen alude al papel que le compete a la nueva generación, a los jóvenes, a la innovación permanente. Bajo esta premisa, Zulen puede ser ubicado en lo que Thomas Sowell Ilama Visión no Restringida ${ }^{48}$. En efecto, Zulen pasó del positivismo al pragmatismo, pero siempre teniendo como base la idea de un ser humano capaz de modificar su entorno, que manifiesta permanente rebeldía frente a lo dado. De aquí se deriva su pensamiento político. En efecto, su concepción sobre el ser humano sustenta su proceso de radicalización cuando enfrenta el problema del indio, a quien consideraba -en contra de la intelectualidad oligárquica oficial - ciudadano y, por tanto, con deberes y derechos como peruanos miembros de un Estado y de una nación ${ }^{49}$. Ello implicaba enfrentarse a los grupos dominantes que le querían escatimar su ciudadanía, es decir, los gamonales y el sistema latifundista bajo el cual vivía en extrema opresión. En numerosas ocasiones se referirá a los indios como parias del sistema vigente.

Zulen sostiene que es necesaria una revolución, como se lo han enseñado "valerosos" hombres, como los delegados de la Pro-Indígena Francisco Mostajo, Francisco Chuquihuanca Ayulo, Luis Felipe Aguilar, Modesto Málaga. Pero entendamos qué es para Zulen revolución: es valor, heroicidad, libre pensamiento, batallar por el ideal, tenacidad, desinterés, abnegación, valentía, solidaridad. Es decir, la revolución es virtud. Elementos que, unidos, hacen patria y nacionalidad, y permiten luchar por los derechos del hombre y del ciudadano, que son esculcados a los indígenas cotidianamente. Por ello, arenga: "... despertaremos a la raza adormecida por el abuso; y la

47 S. Lazarte Oyague, op. cit., 99.

48 Thomas Sowell, Conflicto de visiones, Editorial Gedisa, Barcelona, 1990.

49 Se puede establecer una diferencia sustancial con Riva Agüero. Este sostenía que "la Sierra es la cuna de la nacionalidad", es decir, el territorio, una porción de la geografía; mientras para Zulen son los ciudadanos indígenas los integrantes fundamentales de la nación.

\section{4/ RELUSTA DE SOCOLOOGÍA 26}


despertaremos sin más arma que nuestra fe arrolladora e invicta" ("Revolucionarios, sí; revolucionarios", El Deber Pro-Indígena núm. 30, marzo de 1915) ${ }^{50}$.

Ubicado en una línea de pensamiento que se origina con González Prada, Zulen ya se encuentra en una etapa más radical hacia fines de la segunda década del siglo $X X$. Entiende que los propios indígenas pueden tomar las acciones que lo lleven a su liberación. Es decir, como señala Gerardo Leibner ${ }^{51}$, tramonta su visión paternalista inicial para proponer una alternativa social y política, la misma que encuentra en el socialismo. Volviendo al tema de la revolución, en otro texto su definición adquiere tono más cargado: “Una revolución que cambie radicalmente este estado de cosas, tendrá que ser una revolución agraria, que logre la subdivisión de las haciendas para que no haya ninguna familia peruana sin su lote de terreno propio, aunque reducido, indiviso, inembargable y siempre heredado dentro de su seno. Así no faltará nunca hogar y pan [... ¡ ¡Destruyamos el latifundio! He aquí un lema de la futura revolución social peruana" ("Destruyamos el latifundio", La Autonomía año I, núm. 19, 27 de noviembre de 1915).

Es interesante notar que Zulen extiende su crítica al feudalismo como orden social al terreno de la política, atacando simultáneamente a los partidos políticos y al centralismo perjudicial para la libertad de los individuos cuando señala:"Mientras los pueblos no destruyan estos feudalismos políticos rotulados con el nombre de partidos, interesados como los que más en mantener el centralismo destructor de la nacionalidad, no habrán garantías ni libertades en el Perú. Por eso la campaña anticentralista es la única que hoy puede ofrecer a la nación la esperanza de un ambiente de libertad en un futuro" ("Efectos del feudalismo político", La Autonomía año I, núm. 14, 23 de octubre de 1915).

Zulen se define como libertario. "Permitid que os hable un libertario" —les dice a los ciudadanos de Jauja con motivo de celebrarse el Día del trabajo, 1 de mayo de 1918, actividad auspiciada por la Asociación Obrera - para luego identificarse con la justicia de "las reivindicaciones proletarias". Critica la desigualdad social como una injusticia que ha dado lugar a las divisiones antagónicas en la sociedad, como la lucha de clases. La sociedad moderna apenas ha traído para algunos la libertad, pero muchos siguen esclavizados bajo nuevas formas, como denunció Marx —recuerda-, quien creyó que la solución era la "agitación armada". Pero señala Zulen que también hubo otros socialistas como Eliseo Reclus — viejo luchador anarquista que participó en la Comuna de París-, quien afirmaba que lo más adecuado era

50 Entre las ausencias notorias en los textos de Zulen llama la atención la de la Revolución bolchevique, lo que le hubiera sido útil para contrastar y definir mejor sus propios argumentos.

51 Gerardo Leibner, "Pedro Zulen: del indigenismo paternalista al humanismo radical" European Review of Latin American and Caribbean Studies / Revista Europea de Estudios Latinoamericanos y del Caribe núm. 63, diciembre de 1997. 
ingresar a la vida política como los otros partidos para luchar con ellos en las cámaras legislativas y poder legislar a favor de los trabajadores. Los socialistas empiezan, continúa Zulen, a ingresar a los gabinetes. Recuerda que Woodrow Wilson "declara que el Estado debe intervenir en los conflictos entre el capital y el trabajo, y ponerse al lado de los trabajadores para que no sean víctimas de la tiranía de los capitalistas, y el Congreso Americano da entonces la ley de las ocho horas". En nuestra "nacionalidad enferma" - dice- - "no se ha logrado una conquista práctica en favor de las clases desvalidas". La "raza indígena", mayoritaria en nuestro país, está igual o peor que cuando se fundó la República peruana. Aquí reside el problema social nuestro, en "el verdadero Perú", es decir "en las haciendas y en las minas, donde el empresario amasa su riqueza con la sangre y el sudor de los infelices". Nótese que Zulen vincula el problema social con el problema nacional. La injusticia social atenta contra la constitución de la nacionalidad. Además, es explícito en mencionar las diferencias sociales y el sistema de explotación ("Socialismo y problema social peruano", La Evolución, Huancayo, 7 de mayo de 1918).

Dentro de esta nueva forma de ver nuestros problemas, Zulen sostiene que la derrota de 1879 nos permitió notar "Io ficticio y lo informe de nuestra nacionalidad"; es enfático al denunciar "la farsa institucional que habíamos erigido con el nombre de república". Las riquezas naturales de las que dispusimos (guano, salitre) solo dieron lugar a una "plutocracia nefanda, sin moralidad ni patriotismo". No se hizo nación y se mantuvo a la enorme población indígena analfabeta, sin siquiera los servicios básicos para vivir dignamente; y para empeorar las cosas el extranjero llega y se va con nuestras riquezas dejándonos sin dinero ni para el salario de los trabajadores. Un esbozo de antiimperialismo asoma en sus palabras. A ello se suma el centralismo "que succiona la vitalidad de las provincias" y mantiene al indígena analfabeto y esclavo. No es tarde para regenerarse, sostiene Zulen, "porque el Perú se salvará el día que cada uno de vosotros se sienta Gobierno en su propio terruño, no para mandar ni tener súbditos, sino para constituir, para hacer; que debéis poner vuestro pensamiento en la Patria y ser rebeldes" ("La romería patriótica de Concepción", La Evolución, Huancayo, 10 de julio de 1918).

En su "Discurso a los indígenas de Marco", tenemos a un Zulen crítico y efervescente, elaborando una mirada cuestionadora y al mismo tiempo subversiva para los moldes de su época. Aprovechando la fecha de celebración de la Independencia nacional, Zulen cuestiona si realmente tenemos razones para festejar y ser felices. Contesta negativamente:"... terminado el jolgorio, el indio será siendo la víctima diaria de todas las injusticias". Luego advierte soliviantándolos: "Cuando las autoridades y el gobierno no quieran poner coto y sanción a los abusos, despertarán nuestras conciencias adormecidas, y tendréis que hacer justicia por vuestras propias manos". Y proclama: "El día que

\section{6/REEUSTA DESOCOLOOGIA 26}


un pueblo cansado de sufrir tanto atropello, se levante como un solo hombre y haga un escarmiento, ya nadie se atreverá a cometer los mismos abusos ${ }^{\prime \prime 52}$. La certeza de sus palabras ocasionó que las autoridades, ligadas a los poderes locales, lo encarcelaran. Su encierro duró cinco días, y fue liberado gracias a las gestiones de sus amigos como Tello y Capelo, entre otros. Zulen ya empezaba a resultar incómodo para el orden.

Continuando con sus reflexiones patrióticas, Zulen reitera que a los hombres que conquistaron la Independencia nacional "[l]es faltó la conciencia de la dignidad y la altivez, la integridad de los caracteres. No tuvieron ese ímpetu que encamina a la realización de las cosas supremas y grandes, hasta la heroicidad y el sacrificio. Carecieron de voluntad y ese sentimiento que llevan a la acción y que conducen a las transformaciones de la Historia" (op. cit.). En contraste, señala que está el ejemplo de Vigil, el formidable acusador de los gobernantes, especialmente de Agustín Gamarra. Y continúa con su diatriba: "Vendrá la fecha del (c)entenario de la Independencia y veréis a los oligarcas y opresores, a los explotadores y arribistas, presidir los festejos a la Libertad mientras una raza - que quizás espera la santa redención de un nuevo México - gime a sus pies entre cadenas". En este momento agrega elementos a su concepto de revolución: debe partir de las provincias, al margen de los partidos en vigencia, debe perseguir las garantías y la restitución de sus propiedades a los indígenas, así como combatir al centralismo fomentando la autonomía local y el espíritu municipal que en conjunto hagan efectiva la democracia ${ }^{53}$. Si no somos capaces de cambiar desde nuestras fuerzas internas, sostiene Zulen, la guerra será un "cataclismo necesario", es decir, un factor externo que nos remueva. Es interesante resaltar la visión moderna que Zulen tiene sobre la guerra, a la que reconoce características ambivalentes: "La guerra si es una calamidad material, tiene también la virtud de ser creadora de valores". Pero Zulen persigue un objetivo político, denunciar a las élites y resaltar el patriotismo de los indígenas: “¡Ah! La guerra evidenciará entonces que el defensor de nuestra soberanía y nuestra honra, el guardián de la nacionalidad, es ese paria a quien se roba y se mata diariamente, y que está en nuestras conveniencias conservarle y educarle comenzando por hacerle justicia" ("Una meditación en el 97 aniversario de la Independencia nacional", La Evolución, Huancayo, 28 de julio de 1918). Es singular que se refiera a una guerra externa pero no a una revolución violenta interna.

Zulen agrega más elementos. Dice que la postración del indio proviene desde los tiempos del Virreynato, pero la República ha mantenido el error: “Esta

52 Discurso pronunciado en la plaza principal de ese pueblo en las Fiestas Patrias de 1918. Claridad núm. 6, octubre de 1924.

53 Otra ausencia en los textos de Zulen es la Revolución mexicana, que no aparece en sus reflexiones, a pesar de su agrarismo que pudo haberle permitido establecer comparaciones con el caso peruano. 
tampoco ha reconocido que el indio es y tiene que ser el factor primo de nuestra nacionalidad" ("El Perú en su primera centuria republicana", La Prensa, Nueva York, 28 de julio de 1921). Es claro que para Zulen el sujeto político por excelencia es el campesino-indígena.

Nuestro filósofo perteneció, intelectualmente hablando, por sus conocimientos y reflexiones, a lo que en su tiempo se llamó "aristocracia de la inteligencia", pero socialmente era parte del mundo plebeyo de Lima que no se comunicaba necesariamente con aquella élite. Es decir, no estaba integrado plenamente a la sociedad oficial —aunque reunía todas las condiciones para ello-, pero tampoco era un total marginado. Sus méritos intelectuales como filósofo y pensador social eran escamoteados por su procedencia social y cultural, pero al mismo tiempo su condición plebeya podía ser soslayada en parte por su importancia como sujeto de ideas. En la experiencia personal de Zulen convivieron, pues, dos mundos incompletos y hasta contradictorios, conflicto que quiso resolver infructuosamente con su incorporación en la vida política.

No alcanzó Zulen a redondear una visión integral del país, la muerte lo sorprendió en pleno proceso de madurez intelectual e ideológica. Nunca sabremos hacia qué rumbos se hubiera dirigido, ni si su evidente radicalismo lo hubiera acercado al marxismo o si hubiera llevado a sus límites el liberalismo humanista ${ }^{54}$, pero la vida es la sucesión de grupos humanos que enriquecen cada tanto el pensamiento y amplían el conocimiento heredado. Lo que dejó de hacer Zulen tratarán de llevarlo a cabo otros intelectuales de generaciones posteriores a la suya, quizás sin saberlo y algunas veces sin reconocerlo. Pero debemos tener en cuenta que cuando murió, en 1925, ya Mariátegui había iniciado sus análisis de la realidad peruana y mundial desde el marxismo, y que el aprismo empezaba a tomar forma. Es decir, que si hubiera vivido más tiempo, Zulen habría tenido opciones a las cuales adscribirse o, quién sabe, proponer una nueva alternativa de comprensión desde la postura radical ya iniciada. Menos plausible es que se hubiera asimilado a la corriente social-cristiana representada por Belaunde, tanto porque no era un creyente ${ }^{55}$ como por no ser suficientemente radical para lo que su pensamiento y su espíritu ya demandaban.

Zulen se adscribía al socialismo-parlamentario, es decir, defender los derechos de todos los ciudadanos de pertenecer a una comunidad política, al Estado, a la nación, y desde sus propios procedimientos e instituciones; al mismo tiempo, mediante leyes que permitan la incorporación de todos como ciudadanos, buscar modificar las bases del injusto sistema social. Aquí ingresa el tema de la moral. En cierta medida,

54 Un hecho que demuestra que Zulen estaba en busca de un camino propio es su rechazo a la iniciativa de Luis Ulloa de fundar un Partido Socialista en 1919. Coincidentemente, al igual que Mariátegui.

55 Véase "La Religión y la Ciencia (A través de libros recientes)", La Prensa, 14 de febrero de 1909. Aunque respetaba las creencias diversas: “La tolerancia de cultos", La Autonomía año 1, núm. 17, 13 de noviembre de 1915. 
sus postulados lo acercan a lo que Carlos Roselli denominaría socialismo-liberal en los inicios de los años veinte $e^{56}$.

En cuanto al contexto social peruano, como es conocido, la vida nacional estaba marcada por el llamado problema del indio. Constantes levantamientos de campesinos en diferentes partes del país, reclamos persistentes ante las autoridades por los derechos sobre sus tierras, enfrentamientos contra los poderes locales y, sobre todo ello, una abundante discusión ideológico-política sobre la situación del indio que dio espesura a una nueva conciencia pública sobre el tema.

Zulen solo pudo conocer parte de dichas reflexiones, a las que él mismo contribuyó desde que fundó la Pro-Indígena y su órgano de difusión, El Deber Pro-Indígena, aunque sí fue testigo de una situación social que denunció permanentemente. En el duelo periodístico sobre el tema del indio que protagonizaron Mariátegui y Sánchez es factible que se hubiera ubicado al lado del primero tanto por el tema del socialismo como por su conocida oposición intransigente al gamonalismo; aunque no debemos menospreciar el peso de la afinidad personal que sentía por el Amauta. Por otra parte, desde el terreno político, el Estado se había mostrado incapaz e insensible ante la situación del indio, ante lo que seguramente Zulen habría ejercido una crítica constante. No olvidemos que vivió la primera mitad de lo que fue el oncenio, y el leguiismo si bien creó algunas instituciones para enfrentar dicho problema, no llegó a eliminar el poder del latifundismo.

En términos generales, Zulen trasluce una visión optimista de la vida (otra característica de la Visión No Restringida sobre el ser humano) al considerar que el esfuerzo de los individuos puede modificar para mejor el orden de cosas; no hay inmutablidad en las condiciones sociales. Sus referencias al socialismo y a la revolución deben ser entendidas dentro de esa convicción. Tampoco Zulen es un intelectual que se dirige a los políticos, no los quiere convencer de nada; él se dirige a los de abajo, enfáticamente a los indígenas, a quienes consideraba la base del verdadero Perú, aunque esto no implicaba una visión racista, sino universalista al considerar a los indígenas como individuos, lo que el Perú oficial oligárquico se negaba a reconocer. Ello constituyó una verdadera conmoción conceptual en su momento.

56 José Vidal-Beneyto define al socialismo liberal como "una filosofía de la libertad que hace de la autonomía del individuo al mismo tiempo su arma de combate y su objetivo final" (El socialismo liberal/1, El País, 10 de mayo de 2008). Definición muy congruente con lo que Zulen sostenía. Un análisis más amplio se puede encontrar en el artículo de José Fernández Santillán, "Carlo Rosselli: el compromiso intelectual ante el liberalsocialismo", en Laura Baca Olamendi e Isidro H. Cisneros (editores), Los intelectuales y los dilemas políticos en el siglo XX, Flacso-Triana editores, Ciudad de México, 1997. 